18 Casualty Surgeons' Association. Accident and emergency department handbook. Loughborough: 3 M Healthcare Ltd, 1990.

19 Dean AG, Dean JA, Burton AH, Dicker RC. Epi Info Version 5: a word processing, database and statistics program for epidemiology on microcomputer. Stone Mountain, Georgia: USD Incorporated, 1990 .

20 Williams E, Pottle B. The ups and downs of accident and emergency. Nursing Times 1989;85(47):60-4

11 Burcher B, Elliot D A sampling errors manual. London: OPCS/HMSO, 1990.

22 National Audit Office. NHS accideit and emergency departments in England. London: HMSO, 1992.
23 United Kingdom Central Council for Nursing, Midwifery and Health Visiting. The scope of professional practice. London: United Kingdom Central Council, 1992

24 United Kingdom Central Council for Nursing, Midwifery and Health Visiting. Code of professional conduct. 3rd ed. London: United Kingdom Central Council, 1992.

25 Department of Health. The extended role of the nurse/scope of professional practice. London: Department of Health, 1992. (PL/CNO (92) 4.)

(Accpted 14 October 1992)

\title{
Regional transfusion centre preoperative autologous blood donation programme: the first two years
}

\author{
Martin R Howard, Catherine E Chapman, Judith A Dunstan, Christine Mitchell, Huw L Lloyd
}

\section{Abstract}

Objective-To assess the efficacy of a regional autologous blood donation programme.

Design-Clinical and laboratory data were collected and stored prospectively. Transfusion data were collected retrospectively from hospital blood bank records.

Setting-Northern Region Blood Transfusion Service and 14 hospitals within the Northern Regional Health Authority.

Subjects-505 patients referred for autologous blood donation before elective surgery.

Main outcome measures-Patient eligibility, adverse events from donation, autologous blood units provided, and autologous and allogeneic blood units transfused within $\mathbf{1 0}$ days of operation.

Results-Of 505 patients referred, 354 donated at least one unit. 78 of 151 referred patients who did not donate were excluded at the autologous clinic, mostly because of anaemia or ischaemic heart disease. In 73 cases the patient, general practitioner, or hospital consultant decided against donation. 363 autologous procedures were undertaken. In 213 $(59 \%)$ cases all requested units were provided. The most common reasons for incomplete provision were late referral or anaemia. Adverse events accompanied 24 of 928 donations $(2 \cdot 6 \%)$. Transfusion data were obtained for 357 of the 363 procedures. 281 donors were transfused; autologous blood only was given to 225 , autologous and allogeneic blood was given to 52 , and allogeneic blood only was given to four. 648 of $902(72 \%)$ units of autologous blood were transfused. Complete provision of requested autologous units was followed by allogeneic transfusion in 12 of 208 procedures $(5 \cdot 8 \%)$. Incomplete provision was followed by allogeneic transfusion in 44 of 149 procedures $(30 \%)$.

Conclusions-This study shows the feasibility of a regional autologous transfusion programme. Autologous donors only infrequently received allogeneic transfusion. Patients should be appropriately selected and referred early.

\section{Introduction}

Autologous blood provides an alternative to blood from volunteer donors for patients undergoing elective surgical procedures. Although autologous transfusion has been practised intermittently for 100 years, there has recently been increased interest in the procedure. This has arisen partly from a heightened public awareness of the infective risk of blood transfusion and partly from the increasing demand for blood from volunteer donors. Potential advantages of autologous transfusion include the avoidance of blood transmitted infection, alloimmunisation, and transfusion related lung injury.
There is a small but definite risk of acquiring $\vec{\omega}$ infection from transfused allogeneic blood. Dodd $\bar{T}$ suggested that about three in 10000 blood recipients in 3 . the United States contract serious or fatal transfusion $\omega$ transmitted infection.' Estimates of the risk of HIV transmission by transfusion in the United States range from one in 225000 per unit transfused ${ }^{2}$ to one $V$ in $60000 . .^{3+}$ We have estimated the risk of HIV-1 $\vec{A}$ transmission by allogeneic blood in the United $\partial$ Kingdom using Hickman's modification of a formula응 proposed by Ward et al. ${ }^{50}$ Using known incidences of ${ }_{\overrightarrow{ }}$ HIV-1 antibody positivity between 1985 and 1991 of $N$ $0.004 \%$ in first time donors and $0.001 \%$ in repeat donors, ${ }^{7}$ we estimate the risk of HIV-1 transmission $\varnothing$ in the United Kingdom as one in 300000 per unit transfused.

Hepatitis B remains a transfusion risk despite donor screening, but the annual number of acute cases in England and Wales is fairly small. On average 10 cases of acute hepatitis B in which patients had a recordedo history of transfusion (with or without surgery) in the United Kingdom in the six months preceding diag-o nosis were reported to the Public Health Laboratory $\frac{\mathbb{D}}{\mathbb{D}}$ Service Communicable Disease Surveillance Centre each year between 1985 and 1990. This excludes $\overrightarrow{\overrightarrow{0}}$ patients known to have surgically acquired infection $\exists$ (J Heptonstall, personal communication). Donahue et al reported a risk of acquiring post-transfusion? hepatitis C of one per 3000 units transfused in the United States. ${ }^{8}$ The assay used for screening donations for hepatitis $\mathrm{C}$ antibody in their study has already been 0 routinely replaced in Britain and the United States by a more sensitive assay, which is likely to further reduce 8 this risk.

Approximately $0.3 \%$ of routine blood donors haveo unexpected red cell alloantibodies. ${ }^{\circ}$ Such antibodies usually arise after allogeneic transfusion or pregnancy and may complicate future transfusion. Transfusion $\rightarrow$ related lung injury is a life threatening complication of allogeneic transfusion which may be avoided by $\mathrm{N}$ autologous transfusion. ${ }^{10}$

We report the first two years' experience of $a^{-}$ preoperative autologous blood donation programme ino a regional transfusion centre in the United Kindgom. We examine factors which prevented or limited pro- $\stackrel{\oplus}{?}$ vision of autologous blood and assess the incidence of 0 subsequent autologous and allogeneic transfusions in autologous donors.

\section{Patients and methods}

The autologous blood donation programme waso open to patients in the Northern Regional Health Authority who were waiting for a surgical procedure? for which blood would usually be cross matched. Programme documentation was distributed to hospitals within the region. Hospitals within 40 miles $(65 \mathrm{~km})$ 
of the regional transfusion centre were particularly targeted. Patients were referred by surgeons using programme request forms. General practitioner requests were made in collaboration with the referring surgeon.

Patients were eligible for the study if they were considered sufficiently fit to donate blood on more than one occasion. There was no upper age limit. We excluded patients taking angiotensin converting enzyme inhibitors or with any of the following conditions: bacterial infection; unstable angina; angina at rest; severe hypertension; cardiac failure; myocardial infarction within the previous six months; anaemia (haemoglobin concentration $<110 \mathrm{~g} / \mathrm{l}$ at the first visit or $<100 \mathrm{~g} / \mathrm{l}$ at subsequent visits); aortic stenosis; symptomatic cardiac arrhythmia; severe left main stem coronary artery disease; transient ischaemic attacks; cerebrovascular accident; and severe chronic obstructive airways disease. All exclusions were listed on request forms. Entry of children aged less than 10 years was discouraged.

Assessment at the first visit included a medical history and measurements of blood pressure, pulse rate, and haemoglobin concentration. Fully informed, written consent was obtained for venesection and HIV testing. Patients were assessed and bled either at the regional transfusion centre or at the referring hospital by a team from the transfusion centre. Patients had venesection at one to two week intervals. The first unit of blood was collected not more than 34 days and the last unit not less than five days before surgery. Blood (mean 450 (range 405-495) $\mathrm{ml}$ from adults over $48 \mathrm{~kg}$ ) was collected into citrate phosphate dextrose adenosine formula 1 (CPD-A1) anticoagulant solution (Fenwal, Baxter); $250 \mathrm{ml}$ blood packs (Paedipack, Baxter) were used for children. Patients who were taking $\beta$ blockers had venesection with isovolaemic fluid replacement (sodium chloride $(0.9 \% \mathrm{wt} / \mathrm{vol})$ $500 \mathrm{ml}$ ). Oral ferrous sulphate $200 \mathrm{mg}$ three times daily was given from one week before venesection until hospital admission.

Donations were screened and stored at the regional transfusion centre. Each was screened for antibodies to HIV-1, HIV-2, hepatitis C virus (from April 1991), reactivity in the Venereal Disease Research Laboratory test, hepatitis B surface antigen, and irregular red cell antibodies. Blood was sent from the regional transfusion centre to the hospital blood bank at least 24 hours before surgery. Unused blood was returned to the regional transfusion centre for destruction.

Clinical information was collected at entry and at venesection. Details of perioperative transfusion of autologous and allogeneic blood were obtained retrospectively from hospital blood bank records or from hospital case notes. The quantities of autologous or allogeneic blood, or both, issued from the hospital blood bank for each patient within 10 days of operation were recorded.

Statistical methods and definitions-Data were analysed by $\chi^{2}$ test with one degree of freedom and Yates's correction. "Autologous donation" was a single unit of blood reserved for subsequent transfusion into the donor. "Autologous procedure" was a series of autologous donations. "Allogeneic blood transfusion" was blood donated by one individual and transfused into another.

\section{Results}

Between 1 December 1989 and 30 November 1991, 514 requests for autologous donation were received in respect of 505 patients from 14 hospitals in the Northern Regional Health Authority. Of the 354 patients who were accepted, nine donated blood for two surgical operations on different occasions. Thus
363 autologous procedures with donation of one to four units of blood were performed.

A total of 151 referred patients did not donate (table I). In 73 cases the patient, general practitioner, or referring consultant decided against autologous donation before the patient attended the autologous clinic. Seventy eight patients were excluded by the transfusion centre medical officer, most commonly because of anaemia or ischaemic heart disease.

Of the 363 autologous procedures, $116(32 \%)$ were performed in male patients and $247(68 \%)$ in females. The median age was 59 years 1 month (range 10 years 10 months to 84 years 3 months). Table II shows the age distribution. The indications for entry into the programme are detailed in table III. In $245(67 \%)$ of 363 procedures patients were taking medication which would have precluded voluntary allogeneic donation.

Collection of autologous blood-A total of 928 units of blood were collected (mean 2.6 units per procedure); 1135 autologous units had been requested (mean $3 \cdot 1$ units per procedure). Sixteen units were unsuitable for use (volume less than $405 \mathrm{ml}$ (six cases), volume greater than $495 \mathrm{ml}$ (one); time expired (six), processing error (three)). Thus 912 units (mean 2.5 units per procedure) were provided. The regional transfusion centre supplied 224876 units of allogeneic blood during the study, so that the autologous programme

TABLE I-Analysis of 151 patients referred for autologous donation of blood who did not donate

Reaso No of patients Failure to attend autologous clinic after referral $(n=73)$

Patient's decision:

Not fit

Not interested

Social

No reason given

General practitioner's decision

Not appropriate

Hospital's decision

Condition deteriorated

Changed operation date

Intercurrent illness

Rejection by medical officer at first visit $(n=78)$

Anaemia

Ischaemic heart disease

Hypertension

Other cardiac diseas

Bacterial infection

Multiple symptom

Poor venous access

Respiratory disease

Weight less than $48 \mathrm{~kg}$ (and $250 \mathrm{ml}$ pack not available)

Cerebrovascular disease Psychological

TABLE II-Adverse events associated with donation analysed according to age (363 autologous procedures)

\begin{tabular}{lrrrcrrr}
\hline & \multicolumn{6}{c}{ Adverse events } \\
\cline { 3 - 8 } & & & & & & Male/ \\
Age (years) & No & Mild & Moderate & Severe & Total & $\%$ & female \\
\hline 520 & 3 & 0 & 0 & 0 & 0 & 0 & 0 \\
$21-40$ & 60 & 2 & 3 & 0 & 5 & 8 & $1 / 4$ \\
$41-60$ & 134 & 3 & 2 & 0 & 5 & 4 & $2 / 3$ \\
$61-80$ & 157 & 8 & 3 & 1 & 12 & 8 & $4 / 8$ \\
$>80$ & 9 & 1 & 1 & 0 & 2 & 22 & $1 / 1$ \\
\hline
\end{tabular}

TABLE III-Autologous procedures $(n=363)$ analysed by type of elective surgery

\begin{tabular}{|c|c|c|c|c|c|}
\hline \multirow[b]{2}{*}{ Operation } & \multirow[b]{2}{*}{$\begin{array}{c}\text { No of } \\
\text { procedures }\end{array}$} & \multicolumn{2}{|c|}{$\begin{array}{c}\text { Autologous } \\
\text { blood requested }\end{array}$} & \multicolumn{2}{|c|}{$\begin{array}{c}\text { Autologous } \\
\text { blood provided }\end{array}$} \\
\hline & & $\begin{array}{l}\text { Total No } \\
\text { of units }\end{array}$ & Mean & $\begin{array}{l}\text { Total No } \\
\text { of units }\end{array}$ & Mean \\
\hline Hip r & 153 & 608 & $(4 \cdot 0)$ & 451 & $(2 \cdot 9)$ \\
\hline Knee r & 70 & 210 & $(3 \cdot 0)$ & 169 & $(2 \cdot 4)$ \\
\hline Other orthopaedic & 18 & 62 & $(3 \cdot 4)$ & 56 & $(3 \cdot 1)$ \\
\hline Hysterectomy & 80 & 161 & $(2 \cdot 0)$ & 149 & $(1.9)$ \\
\hline General surger & 23 & 59 & $(2 \cdot 6)$ & 52 & $(2 \cdot 3)$ \\
\hline Cosmetic surgery & 13 & 26 & $(2 \cdot 0)$ & 23 & $(1 \cdot 8)$ \\
\hline Urological surgery & 4 & 10 & $(2 \cdot 5)$ & 10 & $(2 \cdot 5)$ \\
\hline Bone marrow donation & 2 & 2 & $(1 \cdot 0)$ & 2 & $(1.0)$ \\
\hline
\end{tabular}


therefore supplied $0.4 \%$ of all red cell units. The request for autologous blood was fully met in 213 $(59 \%)$ of the 363 procedures. Table IV lists the reasons for incomplete collection. The most common reasons were late referral allowing inadequate time for collection, anaemia, intercurrent illness, and side effects from donation. Table III shows the amount of autologous blood requested and provided for various operations. The mean shortfall of provision compared with request was one unit for hip arthroplasty but less for other operations.

Results of laboratory testing-All donations were negative for hepatitis B surface antigen, reactivity in the Venereal Disease Research Laboratory test, and antibodies to HIV-1, HIV-2, and hepatitis C. Irregular blood group antibodies were detected in five patientsanti-Kell (one), anti-Lan (one), anti-D (three).

Adverse events - Adverse events occurred in association with 24 of 928 donations $(2 \cdot 6 \%)$. In one autologous procedure adverse events accompanied two donations. Thus adverse events occurred during 23 of the 363 procedures $(6 \cdot 3 \%)$. Twenty patients who were receiving $\beta$ blocking drugs underwent uneventful isovolaemic donation. In 14 procedures adverse events were mild; symptoms and signs were transitory and limited to pallor, sweating, nausea, faintness, and tachycardia. In nine procedures events were moderate -bradycardia, hypotension, or momentary loss of consciousness. A single event was classified as severe. An 80 year old man with a history of myocardial infarction had a worsening of angina after the second of two uneventful isovolaemic donations. Table II shows the patients' ages and frequency of adverse events. Adverse events occurred less frequently in patients aged 60 or under (10 of 197) compared with those aged over 60 (14 of 166), but this difference was not significant $\left(\chi^{2}=1 \cdot 146 ; p=0 \cdot 28\right)$. Two children aged 10 and 12 years donated uneventfully.

Transfusion-Transfusion information was obtained in 357 procedures (tables $\mathrm{V}, \mathrm{VI}$ ). Two hundred and eighty one autologous procedures were followed by transfusion. Of 902 units of autologous blood that were

TABLE IV-Reasons for incomplete collection of requested autologous blood in 150 autologous procedures

\begin{tabular}{lc}
\hline Reason for incomplete collection & No (\%) of procedures \\
\hline Insufficient time & $53(35)$ \\
Low haemoglobin concentration & $40(27)$ \\
Upper respiratory tract infection & $19(13)$ \\
Other intercurrent illness & $15(10)$ \\
Side effects from donation & $15(10)$ \\
Failure to attend appointments & $3(2)$ \\
Poor venous access & $2(1)$ \\
New disease history & $2(1)$ \\
Psychological & $1(1)$ \\
\hline
\end{tabular}

TABLE V-Blood transfusion after 363 autologous procedures

Nature of transfusion No $(\%)$ of procedures

Autologous only

Autologous and allogeneic

No transfusion

No information

Allogeneic only

$225(62)$

$52(14)$

$76(21)$

$6(2)$
$4(1)$

TABLE VI-Blood transfusion according to type of surgery

\begin{tabular}{lccccc}
\hline Operation & No & $\begin{array}{c}\text { No } \\
\text { transfusion }\end{array}$ & $\begin{array}{c}\text { Autologous } \\
\text { only }\end{array}$ & $\begin{array}{c}\text { Autologous } \\
\text { and allogeneic }\end{array}$ & $\begin{array}{c}\text { Allogeneic } \\
\text { only }\end{array}$ \\
\hline Hip replacement & 152 & 6 & 116 & 27 & 3 \\
Knee replacement & 69 & 5 & 48 & 16 & 0 \\
Other orthopaedic & 18 & 3 & 10 & 5 & 0 \\
Hysterectomy & 80 & 47 & 32 & 0 & 1 \\
General surgery & 20 & 6 & 10 & 4 & 0 \\
Costmetic surgery & 13 & 7 & 6 & 0 & 0 \\
Urological surgery & 4 & 2 & 2 & 0 & 0 \\
Bone marrow donation & 1 & 0 & 225 & 52 & 4 \\
\hline Total & 357 & 76 & & & \\
\hline
\end{tabular}

provided, $648(72 \%)$ were transfused. Transfusion requirements were fully met with autologous blood in 225 of the 281 patients $(80 \%)$ who were transfused. Four autologous donors were transfused only with allogeneic blood in error. Complete provision of the requested quantity of autologous blood was associated with a very low incidence of allogeneic blood transo fusion (12 of 208 procedures; $5 \cdot 8 \%$ ). The incidence allogeneic blood transfusion was higher when the amount of autologous blood provided was less than that requested (44 of 149 procedures $(29.5 \%) ; \chi^{2}$ 르 $35 \cdot 28, \mathrm{p}<0.0001)$. Allogeneic blood was transfuse after 12 of 53 autologous procedures $(23 \%)$ in which late referral had caused a shortfall in the provision autologous blood.

\section{Discussion}

This programme allowed many patients havine elective surgery to avoid transfusion with allogene blood. Most participating patients completely avoideg allogeneic blood transfusion, and others received le allogeneic blood because autologous blood met part their transfusion requirement. For these patients th small risk of infection or immunisation associated with allogeneic blood transfusion was reduced. The maif objective of the programme was therefore achieved. 0

Eligibility criteria for autologous blood donatio have been extensively debated, and several guidelines have been published. ${ }^{11-13}$ Our criteria may seere stringent when it is considered that all the patieng were awaiting general anaesthesia and surgery. How ever, the avoidance of risk of allogeneic transfusiogr must be balanced against the risk of donation. In $\frac{\mathbb{T}}{\mathrm{a}}$ patient with severe cardiovascular disease the risk of $\vec{\Phi}$ hypotensive episode during donation may be judged to outweigh any benefit. The low incidence of adveris events in this and other series ${ }^{1+15}$ suggests that the ris of autologous donation is small. The slight excess of side effects from donation seen in older patients was

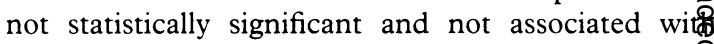
serious consequences. Other reports suggest thaf elderly people may be bled safely. ${ }^{16-18}$

Although elderly patients seem well able to tolerate autologous donation, younger patients have more gain as they have longer to reap the consequences $\Theta$ transfusion transmitted infection. Referral for aut logous donation is dependent on hospital cliniciar rather than transfusion centre staff, but we think the including a greater proportion of younger adults logical. Children require special consideration venesection may be difficult and increase apprehension associated with subsequent surgery.

Patients who donated the full requested quantity of blood subsequently received less allogeneic bloo\& Main causes of incomplete donation were late referra and anaemia. Late referral may be reduced by mo effective communication between the programms organisers and referring clinicians. Anaemia is a mofe refractory problem. Erythropoietin has been used enhance haemoglobin recovery during autologous pro cedures but experience is currently limited to sma studies. ${ }^{19-21}$ Reducing the number of referred ineligible patients would benefit both the patients concerned and the service. The significant rate of non-attendance patients suggests the need for improved patien counselling before entry into the programme.

An advantage of autologous transfusion is reduce demand for limited supplies of allogeneic blood. TH\& impact of the autologous programme on the region blood supply during the study was modest; it provid $0.4 \%$ of the blood issued by the Northern Region Blood Transfusion Service. It has been estimated that autologous blood could provide up to $10 \%$ of all blood requirements. ${ }^{22}$ 
Autologous transfusion does not provide a cheaper alternative to transfusion of allogeneic blood. The cost of producing a unit of autologous blood in our centre is currently about twice the cost of an equivalent allogeneic unit. This difference is due to the staffing and transport costs of the autologous clinics, which are located at several hospitals within the region to allow easy access for patients. If the programme were to expand, allowing venesection of more donors at each clinic, the collection cost per unit would fall.

Unused autologous units were not made available for any other recipient. Most of our autologous donors were taking drugs which would make their blood donation unacceptable for allogeneic use. Also, most autologous units were transfused, those not transfused being held for potential autologous use until expiry or patient discharge. Thus very few units would ultimately be suitable for crossover and procedures for their retrieval are not justified.

We have shown the feasibility of a regional autologous donation programme coordinated by a blood transfusion centre. Main factors which prevented autologous donation were failure to attend the clinic, anaemia, and cardiovascular disease. The main factors which restricted the provision of blood by those who donated were late referral and post-donation anaemia. The aim of avoiding allogeneic blood transfusion was achieved by most patients who donated blood.

We are grateful to the Northern Regional Health Authority for funding and thank all clinicians who entered patients into the programme. We also thank Dr J Conn, Dr J Liston, Dr S Rusby, Sister P O'Brien, Staff Nurse F Jackson, Staff Nurse H Genalis, Mrs C Jefferies, Mrs P Lander, and Mrs S Masterman; the staff of all departments of the Northern Region Blood Transfusion Service; the staff of participating hospital blood banks; and $\mathrm{Mr} \mathrm{D}$ Robinson, of Conway Robinson Associates, for statistical advice.

1 Dodd RY. The risk of transfusion transmitted infection. $N$ Engl $7 \mathrm{Med}$ 1992;327:419-20

2 Petersen LR, Satten G, Dodd RY. Current estimates of the infectious window period and risk of HIV infection from seronegative blood donations. In: Programe and abstracts of the fifth national forum on AIDS, hepatitis and other blood-borne diseases, Atlanta, March 330, 1992. Princeton, New Jersey Symedco, 1992:37.

3 Nelson K, Donahue J, Munoz A, Ness P, McAllister H, Yawn D, et al. Risk of transfusion-transmitted HIV1 and HTLV1/2 [abstract]. Transfusion 1991 31(suppl 85):47S

4 Busch MP, Eble EB, Khayam-Bashi H, Heilbron D, Murphy EL, Kwok S et al. Evaluation of screened blood donations for human immunodeficiency virus type 1 infection by culture and DNA amplification of pooled cells. NEngl f Med 1991;325:1-5.

5 Hickman M, Mortimer JY, Rawlinson VI. Donor screening for HIV: how many false negatives? Lancet 1988;i:1221.

6 Ward JW, Holmberg SD, Allen JR, Cohn DL, Critchley SE, Kleinman SH, et al. Transmission of human immunodeficiency virus (HIV) by blood et al. Transmission of human immunodeficiency virus (HIV) by blood 1988;318:473-8.

7 Gunson HH, Rawlinson VI. Screening of blood donations for HIV-1 antibody: 1985-1991. Communicable Disease Report 1991;1:R144-6.

8 Donahue JG, Munoz DVM, Ness PM, Brown DE Jr, Yawn DH, McAllister $\mathrm{HA}$, et al. The declining risk of post-transion hepatitis $\mathrm{C}$ virus infection. $N$ Engl f Med 1992;327:369-73.

9 Giblett ER. Blood group alloantibodies: an assessment of some laborator practices. Transfusion 1977;17:299-308.

10 Popovsky MA, Chaplin HC, Moore SB. Transfusion-related acute lung injury: a neglected, serious complication of hemotherapy. Transfusion 1992;32: $589-92$

11 British Committee for Standardisation in Haematology, Blood Transfusion Task Force. Guidelines for autologous transfusion. Clin Lab Haematol 1988;10:193-201

12 Committee of Experts on Blood Transfusion and Immunohematology. Council of Europe guidelines for autologous blood transfusion. Vox Sang 1989;57 of Europe

13 Council on Scientific Affairs. Autologous blood transfusions. FAMA 1986; 256:2378-80.

14 Kruskall MS, Glazer EE, Leonard SS, Willson SC, Pacini DG, Donovan LM et al. Utilization and effectiveness of a hospital autologous pre-operative blood donor program. Transfusion 1986;26:335-40.

15 Au Bachon JP, Popovsky MA. The safety of pre-operative autologous donation in the non-hospital setting. Transfusion 1991;31:513-7.

16 Benoit P, Marchand S, Decary F. Blood donation by people aged 70 and over Transfusion Medicine 1992;2:75.

17 Pindyck J, Avorn J, Kuriyan M, Reed M, Iqbal MJ, Levine SJ. Blood

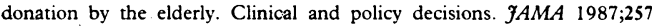
1186-8.

18 Schmidt PJ. Blood donation by the healthy elderly. Transfusion 1991;31:681-3. 19 Goodnough LT, Rudnick S, Price TH, Ballas SK, Collins ML, Crowley JP, et al. Increased pre-operative collection of autologous blood with recombinant human erythropoietin therapy. $N$ Engl f Med 1989;321: $1163-8$.

20 Graf $\mathrm{H}$, Watzinger $\mathrm{U}$, Ludvik B, Wagner A, Hocker P, Zweymuller KK Recombinant human erythropoietin as adjuvant treatment for autologous Recombinant human erythropoietin as

21 Tasaki T, Ohto H, Hashimoto C, Abe R, Saitoh A, Kikuchi S. Recombinan human erythropoietin for autologous blood donation: effects on perioperative red-blood-cell and serum erythropoietin production. Lance 1992;339:773-5.

22 Toy PTCY, Strauss RG, Stehling LC, Sears R, Price TH, Rossi EC, et al. Predeposited blood for elective surgery. $N$ Engl f Med 1987;316:517-20.

(Accepted 6 October 1992)

\section{Servizio di}

Immunoematologia e

Trasfusionale, Ospedale S Croce, USL 58, Cuneo, Italy

G M Peano, deputy consultant in transfusion medicine G Menardi, consultant biologist

$\mathrm{R}$ Balbo, mẹmber of blood bank unit medical staff

D Marenchino, member of blood bank unit medical staff $S$ Fenoglio, chief of blood bank unit

I Divisione di Medicina Generale, Clinica Medica B, Università di Torino, Italy L M Fenoglio, research fellow, gastroenterologist

Correspondence to: Dr Gian Michele Peano, Via Q Sella 22, 12100 Cuneo, Italy.

$B M \mathcal{1}$ 1992;305:1473-4

\section{Heterosexual transmission of hepatitis $\mathrm{C}$ virus in family groups without risk factors}

\author{
G M Peano, L M Fenoglio, G Menardi, R Balbo, \\ D Marenchino, S Fenoglio
}

Alter et al reported finding antibodies to hepatitis $C$ virus (anti-HCV) in most patients with post-transfusion non-A non-B hepatitis. ' Similar findings have been recorded in patients having haemodialysis and in drug misusers. Furthermore, hepatitis $C$ virus may also be detected in patients with chronic liver disease, hepatocellular carcinoma, and chronic alcoholism who have no history of blood transfusions, and variable rates of infection have been recorded in healthy blood donors. We may therefore surmise that risk factors other than direct blood transmission exist. Hepatitis $C$ virus may be transmitted by sexual intercourse. ${ }^{23}$ Other studies, however, have failed to confirm this or shown that it occurs only rarely. ${ }^{45}$

Many of these studies were carried out on heterogeneous groups (homosexuals, drug misusers, haemophilic patients, family groups, etc), so that we still lack conclusive results. We report the role of heterosexual activity and of household contacts in the spread of hepatitis C.virus as determined by studying viral markers in partners and other family members of anti-HCV positive blood donors without known risk factors.

\section{Subjects, methods, and results}

Eighty six blood donors (49 men) were evaluated based on the following criteria: presence of anti-HCV; absence of hepatitis B surface antigen and anti-HIV; no history of drug abuse; in a stable heterosexual relationship (range eight months to 40 years). The subjects were studied in two groups, group 1 being separated into subgroups $1 \mathrm{a}$ and $1 \mathrm{~b}$. Subgroup $1 \mathrm{a}$ comprised 29 cases ( 16 men) of hepatitis $C$ virus related chronic hepatitis confirmed histologically or from a history of increased serum alanine aminotransferase values (above $60 \mathrm{IU} / \mathrm{l}$ ) for more than six months. Subgroup $1 \mathrm{~b}$ comprised 14 subjects (eight men) with a chance finding of abnormal serum alanine aminotransferase activity in the absence of evidence of liver disease. Group 2 comprised 43 subjects ( $25 \mathrm{men}$ ) without a clinical history of liver disease or enzyme abnormality. Sixty eight randomly selected anti-HCV negative blood donors (40 men) served as controls (group 3). Other criteria for selection as controls were as in groups 1 and 2.

Blood donors' partners ( $n=154 ; 65$ men), who were negative for HIV, had no history of drug abuse or other known risk factors, and engaged only in heterosexual activity, were accepted after accurate history taking 